(revised, May 31, 2008)

\title{
Whole Life Satisfaction Concepts of Happiness
}

\author{
by \\ FRED FELDMAN \\ University of Massachusetts at Amherst \\ Amherst, Massachusetts USA
}

Abstract: The most popular concepts of happiness among psychologists and philosophers nowadays are concepts of happiness according to which happiness is defined as "satisfaction with life as a whole". Such concepts are "Whole Life Satisfaction" (WLS) concepts of happiness. I show that there are hundreds of nonequivalent ways in which a WLS conception of happiness can be developed. However, every precise conception either requires actual satisfaction with life as a whole or requires hypothetical satisfaction with life as a whole. I show that a person can be "happy" (in any familiar sense that might be relevant to eudaimonism) at a time even though he is not actually satisfied with his life as a whole at that time. I also show that a person can be "happy" at a time even though it is not correct to say that if he were to think about his life at that time, he would be satisfied with it as a whole. My thesis is that if you think that happiness is the Good, you should avoid defining happiness as whole life satisfaction.

Keywords: happiness, whole life satisfaction, welfare, well-being, prudential value, eudaimonism, Richard Brandt, Wayne Sumner, Elizabeth Telfer, Wladyslaw Tatarkiewicz. 


\section{Happiness and Welfare}

Sometimes, when philosophers talk about happiness, or "the happy life", they are

using the word 'happy' more or less as a synonym of 'good'. ${ }^{1}$ To say that someone had a happy life, in this sense, is pretty much equivalent to saying that he had a good life, or a life high in welfare, or "prudential value". When so used, 'happy' is clearly a term of evaluation. Its meaning is essentially normative. If we use the word in this way, then the statement that the happy life is the good life becomes a tautology, meaning merely that the good life is the good life.

On other occasions, the word 'happy' is used descriptively. To say that a person is happy in this sense is not to evaluate the person but to describe him. Presumably, the description suggests something about the person's mood, or his emotional state, or his state of mind. If we use the word in this descriptive way, then the statement that the happy life is the good life is no tautology. It is a controversial thesis ("eudaimonism") affirming the unique value of some psychological ${ }^{2}$ state. That is a substantive claim and no mere tautology.

\footnotetext{
${ }^{1}$ Earlier versions of this paper were presented at Toronto in December, 2005, Calgary in April of 2006, as the Leonard Lecture at The University of Nevada at Reno in February of 2007, and as the keynote address at the Southwest Graduate Conference at Arizona State University in March of 2007. I am grateful to several people for helpful comments that they provided on those occasions. I especially want to thank Wayne Sumner, Jennifer Hawkins, Gustaf Arrhenius, Owen McLeod, Meghan Masto, Brad Skow, Dan Haybron, Ken Lucey, Peter De Marneffe, Stewart Cohen and Dan Doviak for extensive and useful criticism. I am very grateful to Brad Skow, Chris Heathwood and Owen McLeod for detailed commentaries on an earlier draft. Of course, I am responsible for any mistakes that remain.

2 I say 'psychological' here primarily because so many of the theories about this state imply that it is purely, or largely, a matter of psychology. But I don't mean to beg any questions. I mean just to distinguish between claims about a person's level of welfare (a matter of evaluation) and claims about some "factual" state called 'happiness'. It might not be purely psychological. Perhaps it is partly neurophysiological. My point is that it is some sort of matter of empirical fact.
} 
But this gives rise to a deeper question: precisely what are we saying when we say that a person is "happy" (using the word descriptively)? What is this state that (according to eudaimonism) bears so essentially on welfare? If we don't know what happiness is, then we don't fully understand the eudaimonistic thesis.

A glance at the literature reveals a multitude of theories about the nature of happiness. Mill and others in the utilitarian tradition have said that happiness is fundamentally a matter of pleasure and pain ${ }^{3}$. To be happy, on this view, is to have a positive hedono-doloric balance. Others in the preferentist tradition have said that to be happy to be getting what you want - or in some versions - to be getting what you would have wanted if you had the benefit of full information about your circumstances. ${ }^{4}$ Still others have said other things. ${ }^{5}$ In recent years, however, the most popular view about happiness is "whole life satisfactionism" (WLS). On this view, to be happy is to be satisfied with your life as a whole. A eudaimonist who adopts the WLS approach can be understood to have endorsed two doctrines. The first is an account of the nature of happiness as a psychological state. In some cases it seems to be offered as a theory about what 'happy' means in ordinary English, but more often it seems to be offered as an explication or stipulative definition. The philosopher might say: "For purposes of theory construction, let us understand 'happy' in its descriptive sense to mean 'satisfied with life as a whole"'. The second component of his view is the axiological part. The WLS eudaimonist says that the happier a person is (in his preferred WLS sense of

\footnotetext{
3 "By happiness is intended pleasure, and the absence of pain; by unhappiness, pain, and the privation of pleasure." (Mill, 1962, 257. Emphasis added, FF)

${ }^{4}$ I discuss a view like this below in Section 5 .

${ }^{5}$ For example, there is the "mood theory" defended by Daniel Haybron in Haybron (2001).
} 
'happier'), the better his life is going for him. In other words, a person's welfare level is alleged to be determined by his level of happiness, where happiness is understood to be whole life satisfaction.

WLS concepts of happiness are the subject of this paper. One of my aims is to show that there are many different and inequivalent WLS concepts of happiness. As a result there are at least as many different and inequivalent forms of WLS eudaimonism. My central thesis is that if we make use of a WLS concept of happiness, and then go on to use this concept in a form of eudaimonism, that form of eudaimonism is seriously implausible. $^{6}$

I begin by giving some examples of philosophers who seem to endorse the WLS approach.

\section{Whole Life Satisfaction Theories of Happiness}

WLS concepts of happiness have been proposed by Richard Brandt, John Kekes, Robert Nozick, Wayne Sumner, Wladyslaw Tatarkiewicz, Elizabeth Telfer, G. H. von Wright and many others. While every one of these concepts of happiness requires "whole life satisfaction" in some form or other, they are not equivalent. ${ }^{7}$

\footnotetext{
${ }^{6}$ I also think - though I won't try to establish it here - that WLS definitions of happiness do a poor job of explicating any concept that eudaimonists actually have in mind when they say that happiness is the good. If I am right about this, then anyone who thinks that happiness increases welfare should be inclined to say, 'I think happiness is the good; and I think the concept of happiness is obscure; but I surely do not think that happiness should be defined as being satisfied with your life as a whole.'

${ }^{7}$ Each of these philosophers offers a WLS concept of happiness. In some cases it is offered simply as an account of the nature of happiness. In other cases it is offered as a stipulative definition as part of a larger
} 
a. Tatarkiewicz says that happiness (in the most important sense of the term) is 'satisfaction with one's life as a whole.'(Tatarkiewicz, 1966: 1) He apparently means to defend the view that if a person is happy then he must not only be fully satisfied with the current segment of his life, he must be satisfied with the past segment of his life and the segment of his life that is yet to come. ${ }^{8}$ In his discussion of happiness and time he makes the point explicitly:

Satisfaction with life as a whole must be satisfaction not only with that which is, but also with that which was and that which will be, not only with the present, but also with the past and the future. (Tatarkiewicz, 1976: 140).

b. Elizabeth Telfer (Telfer, 1980) formulates the theory in a different way. ${ }^{9}$ She says:

My suggestion for a definition of happiness, then, is that it is a state of being pleased with one's life as a whole...(Telfer, 1980: 8-9)

\section{Telfer expands upon this by saying that 'a happy man does not want anything} major in his life to be otherwise; he is pleased with, that is wants (to keep), what he has

project about welfare. In yet other cases it is offered in other ways. I do not mean to suggest that all of these philosophers propose the same account of happiness, or that they use the account of happiness in the same way.

${ }^{8}$ Tatarkiewicz acknowledges that 'happy' is multiply ambiguous and vague in ordinary language. He claims, however, that in one of its two main ordinary senses, it means satisfaction with life as a whole. He claims that this is the crucial sense since happiness, thus understood, is "one of the greatest goods accessible to man." (Tatarkiewicz, 1976: 4) After further reflection, Tatarkiewicz revises this account, saying instead that ideal happiness is "lasting, complete, and justified satisfaction with life." (Tatarkiewicz, 1976: 16)

9 Telfer also claims that 'happy' is ambiguous in ordinary language. Like Tatarkiewicz, she claims that in the most important sense, and the sense of greatest interest to moral philosophers, it expresses the concept of whole life satisfaction. 
got; there is nothing major which he has not got and which he wants (to get).'(Telfer, 1980: 8)

c. Richard Brandt (Brandt 1967) states two conditions for happiness. Brandt says:

....the following proposal for a definition of "happy" may be suggested. ... in order to be happy it is necessary that one like ... those parts of one's total life pattern and circumstances that one thinks are important. To say that one likes them is in part to say that one is "satisfied" with them - that one does not wish them to be substantially different, and that they measure up, at least roughly, to the life ideal one had hoped to attain; ... [We] would not call a man happy if he did not frequently feel joy or enthusiasm or enjoy what he was doing or experiencing.(Brandt, 1967: 413-4)

Brandt apparently means to be proposing an account of what it means to say that a person had a happy life, or was a happy person. His idea seems to be that in order to be a happy person, one must meet two conditions. First, one must be satisfied with the life one in fact has lived - that life must measure up (or must be believed to measure up) sufficiently to the "life ideal" one had hoped to attain. Secondly, one must have felt joy or enthusiasm frequently during that life. 
d. Like Brandt, Wayne Sumner claims that in order to have a happy life, a person must

(a) be satisfied with his life as a whole, and (b) enjoy certain moods or emotions. ${ }^{10}$

Sumner describes the first component in these words:

The cognitive aspect of happiness consists in a positive evaluation of the conditions of your life, a judgement that, at least on balance, it measures up favourably against your standards or expectations. This evaluation may be global, covering all of the important sectors of your life, or it may focus on one in particular (your work, say, or your family). In either case it represents an affirmation or endorsement of (some or all of) the conditions or circumstances of your life, a judgement that, on balance and taking everything into account, your life is going well for you. (Sumner, 1996: 145)

The second component of Sumner's analysis is the affective component. Sumner requires that a happy person experience "a sense of well-being" that is directed upon a specific object - his life as a whole.

The affective side of happiness consists in what we commonly call a sense of well-being: finding your life enriching or rewarding, or feeling satisfied or fulfilled by it. (Sumner, 1996:

Views relevantly like these have been proposed by many other philosophers and psychologists. But for present purposes this brief catalogue should be sufficient. All

\footnotetext{
${ }^{10}$ Neither Sumner nor Brandt claims that a person's welfare level is directly determined by the amount of happiness he enjoys. Sumner, for example, claims that welfare 'consists in authentic happiness, the happiness of an informed and autonomous subject.' (Sumner, 1996:172)
} 
these definitions - and others relevant ly like them - introduce WLS concepts of happiness.

\section{Two Preliminary Problems}

WLS conceptions of happiness seem to confront two closely related problems right at the outset. For purposes of discussion, imagine a view (like Brandt's or Sumner's) according to which a person is happy iff he judges that important aspects of his life match up with his expectations. One problem arises because a person might judge at one time that important aspects of his whole life do match up with his expectations; but the same person might judge at another time that important aspects of his whole life do not match up with his expectations. This sort of change in judgment is unproblematic in itself. Just as your blood pressure may vary through time, so may the extent to which you judge that important aspects of your life as a whole match up with your expectations. ${ }^{11}$ However, the advocate of the WLS concept of happiness surely does not want to say, in such a case, that the person both did have a happy life and also did not have a happy life. That would simply be a contradiction. This is the instability problem.

A second problem is generally known as the lability problem. Empirical testing has demonstrated that an individual's judgment about whole life satisfaction can be

\footnotetext{
${ }^{11}$ In Diener et al. (1985) Ed Diener and his colleagues present a little questionnaire designed to determine a person's satisfaction with life. They claim that their Satisfaction With Life Scale has "favorable psychometric properties". Among these properties is "high temporal reliability". People tend to get the same score on this scale when they retake the test two months later. I cannot imagine why Diener et al. think that this sort of reliability is a "favorable psychometric property". Surely the corresponding feature in a blood pressure test would be cause for concern about the test. Similarly, unless we have independent reason for thinking that happiness levels remain constant through life, temporal reliability is neither "favorable" nor unfavorable.
} 
affected by seemingly trivial features of the context in which he is making the judgment. ${ }^{12}$ Thus, for example, if a subject is first allowed to discover a "lost" dollar bill, and then is asked to make a judgment about whole life satisfaction, he is likely to indicate greater satisfaction than he would if he had not found a free dollar bill. Many other contextual factors - the weather, the decor of the room in which the subject is questioned, the attractiveness of the questioner -- are seen to affect life satisfaction judgments. This seems to suggest that such judgments are somehow "wrong" - that they fail to track our actual levels of life satisfaction. The idea that a subject genuinely becomes more satisfied with his life as a whole simply because he came across a dollar bill seems incredible.

Some have suggested that these problems could be avoided if there were some ideal moment for measuring life satisfaction. For example, we might say that a person has a happy life if, at the moment of death, when he looks back and surveys his life as a whole, he judges that important aspects matched up with his expectations. The problems with this approach should be obvious: some people don't look back and survey their lives on their deathbeds. Some who do thus survey their lives may make a favorable judgment even though they in fact led miserable lives; others may not make favorable judgments even though their lives were very happy. Surely it is unreasonable to link a person's lifetime happiness level to the life-assessment he makes in extremis.

I believe, however, that neither instability nor lability is a genuine problem. In each case, a problem seems to arise primarily because the theory has not been formulated

\footnotetext{
${ }^{12}$ For a popular sketch of some of the relevant research, see Nettle (2005): 34-6.
} 
clearly. In order to state it clearly, we must start by drawing a distinction between two WLS concepts. The fundamental concept is a concept of whole life satisfaction at a moment. This is just the amount of the relevant sort of whole life satisfaction that a subject has at a moment. The second concept would be a concept of whole life satisfaction during an interval based upon some sort of aggregation of information concerning whole life satisfaction levels at moments within the interval. ${ }^{13}$

Let me sketch one way of making use of this distinction. Suppose a subject, $\mathrm{S}$, is satisfied with his life as a whole to different degrees at different moments. At $t 1$, he is satisfied to degree 4 with his life as a whole. At $t 2$, he is satisfied to degree 6 , and so on. Suppose he is dissatisfied with his life as a whole at some other moments during the interval. At t16, for example, he is satisfied to degree -2 with his life as a whole. If all of these momentary satisfaction-with- life-as-a-whole levels are plotted on a graph, we get a line as follows:

\footnotetext{
13 For a discussion of this so-called "instability problem" and a different solution, see Valerie Tiberius (unpublished). I dis cuss this approach later in Section 5.
} 


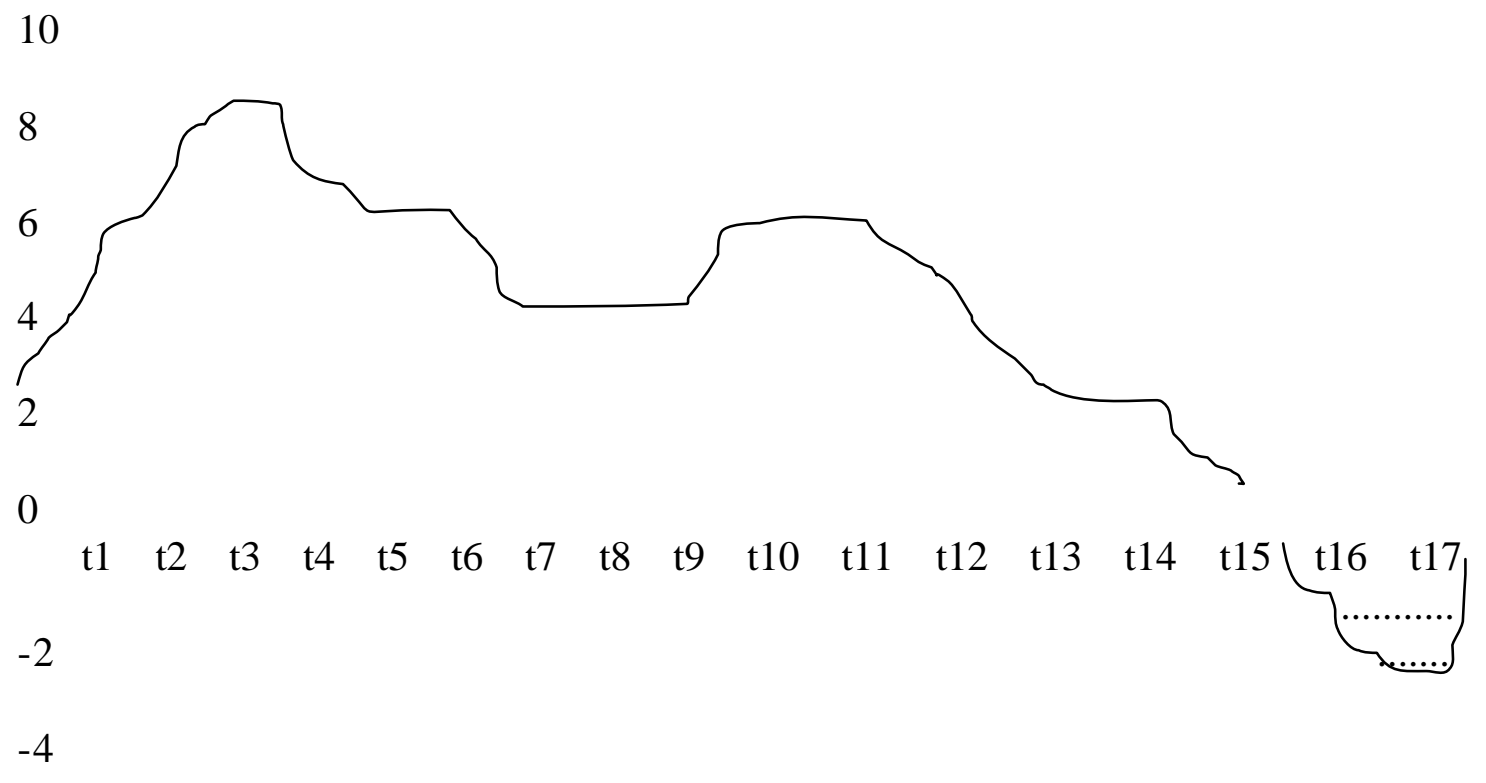

\section{Graph 1}

We can define the subject's whole life satisfaction for the interval t1-t17 simply as the integral of his momentary life satisfactions for the moments during the interval. Thus we recognize the fact that whole life satisfaction varies from time to time. We incorporate this fact into our calculations, letting life satisfaction during a stretch of time be determined (roughly) by the total amount of life satisfaction the person experiences during that time, minus the total amount of life dissatisfaction. ${ }^{14}$

Advocates of the WLS approach to happiness can then say that a person's happiness at a moment is equal to his level of whole life satisfaction at that moment; and happiness in life as a whole is equal to his whole life satisfaction for the interval that is his whole life. The fact that there were times when he was not satisfied with his life as a whole does not introduce a contradiction; it just lowers his net whole life satisfaction

\footnotetext{
${ }^{14}$ There are other ways of doing the aggregating. We might focus instead on average levels of momentary life satisfaction; we might focus on highs and lows; there are other options. I presuppose this method of aggregation primarily for simplicity in exposition.
} 
level and thus his total amount of happiness in life. Thus the instability problem does not arise.

What of the lability problem? Suppose a subject finds a lost dollar bill at a certain time. Suppose that a moment later he judges his life as a whole to be going very well. Suppose he would not have made such a favorable judgment about his life as a whole if he had not found the dollar bill. Must we then worry that his judgment is somehow "wrong" and needs to be disregarded in our calculations? I think not. I think this lability is not a problem. Advocates of the WLS approach should just recognize that in fact subjects are temporarily made somewhat happier by seemingly trivial facts. Their outlook on life as a whole can be brightened even by finding a lost dollar bill or sitting in an interview room with an attractive interviewer. Thus, there is nothing wrong with saying that they are somewhat happier (for a moment) even though the increase in happiness is based on quite a trivial factor. ${ }^{15}$

If we choose to formulate the theory in this way the crucial question concerns whole life satisfaction at moments. Precisely how are the satisfaction-with-life-at-amoment points determined?

\section{Some Distinctions and a Multitude of Concepts}

\footnotetext{
${ }^{15}$ In Chapter 4 of his forthcoming book, Daniel Haybron discusses this problem. He points out that some researchers worry that this "fickleness" of life satisfaction reports indicates that such reports have "little grounding in any important reality and are not to be taken seriously'. (Haybron, forthcoming, Ch. 4)
} 
It should be obvious even from the smattering of quotations at the outset that it is not the case that advocates of the WLS approach have committed themselves to precisely the same view. Let us consider some of the respects in which these formulations differ.

a. Some of these formulations suggest that whole life satisfaction is something very "cognitive" and "judgmental". Others suggest that it is something much more emotional. According to a judgmental view, in order to be satisfied with his life a person must make a judgment about his life - perhaps (as Sumner says) the "judgement that, on balance and taking everything into account, your life is going well for you." According to a more emotional view, it would not be necessary to make any judgment. All that would be necessary is that the person should "feel good" about his life as a whole. Telfer seems to advocate this sort of approach. She says that what's necessary is that you be "pleased with" your life as a whole. It should be obvious that a person could "feel good" about his life without making any judgment, and that a person could make a judgment without "feeling good" about anything. Brandt and Sumner apparently want to say that happiness involves both something judgmental and something emotional. ${ }^{16}$

b. Some of these formulations suggest that happiness essentially involves making a judgment about one's life as a whole. This provides the rationale for the name of the theory. Tatarkiewicz clearly opts for something like this. But other formulations weaken the requirement. They say that happiness essentially involves making a favorable judgment about important aspects of the life. Brandt, Sumner, and Telfer all say things

\footnotetext{
${ }^{16}$ Tatarkiewicz seems also to opt for a conception of satisfaction that involves both an intellectual and an emotional element. (Tatarkiewicz, 1976: 12)
} 
like this. Sumner seems to commit himself to a still weaker view. In one parenthetical remark, he says that happiness requires merely that the subject make a favorable judgment about some aspect of his life. ${ }^{17}$ Clearly, a person could judge that some aspect of his life is going well without judging that any important aspect of his life is going well; and he could judge that some important aspect is going well without judging that all the important aspects are going well; and a person could judge that all important aspects are going well without judging that the life as a whole is going well.

c. There is a striking difference between versions of the view according to which the happy person must actually make the judgment of life satisfaction, and versions according to which the happy person must merely be such that he would have made such a judgment, if he had thought about the matter (or if some other counterfactual condition had been satisfied). Tatarkiewicz clearly chooses the hypothetical version when he says, 'it is enough that he would be satisfied if he were to think of it'. (Tatarkiewicz, 1976: 10) Again, the difference is obvious. Someone might never think about his life as a whole, and might never form any judgment about whether it was satisfactory, yet he might be the sort of person who would have formed a favorable judgment about his life, if he had given it any thought. Let us introduce some terminology here to mark this difference. An actualist view would say that such a person is not happy because he did not actually

\footnotetext{
${ }^{17}$ Sumner says that a person is happy if she is satisfied with "some or all of the conditions or circumstances of her life" (Sumner, 1996: 156). I am puzzled by the suggestion that a person could be declared happy if she were satisfied with merely some of the conditions of her life. Surely that is far too weak. Suppose she is profoundly dissatisfied with most of the conditions of her life (including her health, her wealth, her level of freedom, her marriage, and her job), but satisfied with just two minor ones (her internet access is fast; her TV reception is good). Perhaps (though he never says quite this) Sumner's idea is rather that a person is happy in a certain area of life iff she is satisfied with the conditions of her life in that area.
} 
form the judgment; a hypotheticalist view would say that he is happy because he would have formed the judgment if he had given it some thought.

d. Tatarkiewicz claims that to be happy one must be satisfied with one's whole life - past, present, and future. It appears that his idea was that the ideally happy person somehow conceives of everything that has happened to him, that is happening to him, and that ever will happen to him. He is fully satisfied with all of it, from beginning to end. ${ }^{18}$

Tatarkiewicz recognizes that this is beyond the intellectual powers of any actual human being and accordingly concludes that no one is happy (in this robust "ideal" sense). A different view would maintain that to be happy at a time one must be satisfied with the temporal slice of one's life that is then current. Perhaps an advocate of this approach would say that to be happy in life as a whole is to be happy at enough of these moments. This could happen even if there was no moment at which the happy person were satisfied with anything in his past or future relative to that moment. ${ }^{19}$ Yet another view would maintain that to be happy at a time requires that one be satisfied with everything that has happened to him up until that time. ${ }^{20}$

e. There are people who are confused about their lives. They think certain things have happened to them, but in fact those things have not happened. We might say that happiness requires being satisfied with the things that have actually happened in your life

\footnotetext{
${ }^{18}$ This comes out especially clearly in one of the passages I cited earlier: "Satisfaction with life as a whole must be satisfaction with that which is, but also with that which was, and that which will be, not only with the present, but also with the past and the future."(Tatarkiewicz, 1976: 140)

${ }^{19}$ There might then be a question about the extent to which such a view still deserves to be classified as a form of "whole life satisfactionism". But if we aggregated information about momentary satisfaction levels so as to generate the subject's whole life satisfaction level, the resulting theory would be in important respects similar to the other theories under consideration here.

${ }^{20} \mathrm{I}$ am not aware of anyone who actually defended this view.
} 
as a whole. Alternatively, we might say that happiness requires being satisfied with the things that you think have happened to you in your life as a whole. Depending upon the details of formulation, these views could yield different judgments concerning the case of a person who is mistaken about what has happened to him. I will characterize a view as a form of "objectivism" if it says that happiness requires satisfaction with the life you are actually living. I will characterize a view as a form of "subjectivism" if it says that happiness requires satisfaction with the life you think you are living. ${ }^{21}$

f. When we say that a person is satisfied with his life, we may have in mind (a) that he has a very detailed conception of what has happened in his life, and he is satisfied with that; or we may have in mind (b) that he has only a vague and superficial conception of what has happened in is life, but that (insofar as he is aware of it) he is satisfied with that. Thus there is a further dimension on which WLS definitions of happine ss can be located. This dimension involves the degree of detail and specificity of awareness that is required for happiness. Let us say that a definition is "maximally epistemically demanding" if it requires that the happy person have a complete and detailed conception of his own life; let us say that it is "epistemically lax" if it requires no such detail. Obviously, there are many intermediate degrees of demandingness between these extremes. For every such degree, there is a collection of distinct forms of WLS.

These are six independent distinctions. Judgmentalism can be combined either with actualism or with hypotheticalism; important aspectivalism can be combined with currentism or with up-to-nowism. The same is true for all the distinctions. The result is

\footnotetext{
${ }^{21}$ In choosing this terminology to mark this distinction I follow Tatarkiewicz in (Tatarkiewicz, 1976: 16)
} 
that we can formulate hundreds of different WLS definitions of happiness. Let's briefly consider some of the possibilities.

We can formulate a definition of happiness that is (a) judgmental, (b) "important aspectival", (c) actualist, (d) up-to-now-ist, (e) objective, and (f) moderately epistemically demanding. It looks like this:

WLS6: A person, $\mathrm{S}$, is happy to degree $\mathrm{n}$ at a time, $\mathrm{t},=\mathrm{df}$. there is a certain life that $\mathrm{S}$ has actually lived up to t, and at $\mathrm{S}$ actually has a life ideal, and at $\mathrm{t}, \mathrm{S}$ knows what his life ideal is and has a moderately detailed conception of what has transpired in important aspects of his life up to $t$, and at $t, S$ judges with respect to the up-to-t segment of his life that important aspects of that life segment match up to degree $n$ with the life ideal that he maintains at $\mathrm{t}$.

A different definition would replace the (b) "important aspectivalism" of WLS6 with "universalism". It would also replace the (d) "up-to-now-ism" with "current slicism". The resulting definition is:

WLS7: A person, $\mathrm{S}$, is happy to degree $\mathrm{n}$ at a time, $\mathrm{t},=\mathrm{df}$. there is a certain slice of life that $\mathrm{S}$ is actually living at $\mathrm{t}$, and at $\mathrm{t} \mathrm{S}$ actually has a life ideal, and at $\mathrm{t} \mathrm{S}$ knows what his life ideal is and $\mathrm{S}$ has a moderately detailed conception of what is transpiring in the current slice of his life at $\mathrm{t}$, and at $\mathrm{t} \mathrm{S}$ judges with respect to the current-at-t slice of his life that it matches up as a whole to degree $\mathrm{n}$ with the life ideal that he maintains at $\mathrm{t}^{22}$

\footnotetext{
${ }^{22}$ It may seem that WLS7 is not a genuine form of whole life satisfactionism, since the holistic elements of other versions seem to be missing. But it is important to keep in mind that WLS7 gives the criterion for
} 
By making suitable substitutions, we can construct hundreds of other WLS concepts of happiness. No pair of these will be exactly equivalent. They give different accounts of happiness at a moment; accordingly, they yield different assessments of happiness in intervals and lives. My claim is that no matter which one we adopt, the version of eudaimonism based on it is seriously implausible.

\section{Actualism and Hypotheticalism}

Obviously, however, a detailed discussion of all these WLS concepts of happiness would be tedious. I will proceed in a different way. I will focus on the distinction between actualism and hypotheticalism. First, I will attempt to show that any actualist WLS definition of happiness generates an implausible form of eudaimonism. Then I will attempt to show that any hypotheticalist WLS definition of happiness generates an implausible form of eudaimonism. Since every WLS concept of happiness is either actualist or hypotheticalist, this should suffice to show that none of them figures in a plausible form of eudaimonism.

Let's consider a form of actualism that is judgmentalist, holistic, temporally universal, objective, and epistemically demanding:

happiness at a moment; to determine how happy a person is in life as a whole, we would have to determine the implications of WLS7 for every moment in the person's life and then aggregate the results. Thus, the holism would return when it comes time to do the aggregating. 
WLS1: A person, $\mathrm{S}$, is happy to degree $\mathrm{n}$ at a time, $\mathrm{t},=\mathrm{df}$. there is a certain life that $\mathrm{S}$ actually will end up having lived, and at $\mathrm{t} S$ actually has a life ideal, and at $\mathrm{t}, \mathrm{S}$ knows what his life ideal is and has a detailed conception of what will transpire in his life as a whole, and at t, S actually judges with respect to his whole life (from beginning to end) that it matches up to degree $\mathrm{n}$ with the life ideal that $\mathrm{S}$ maintains at $\mathrm{t}$.

In addition to being actualist, WLS1 is highly judgmental. It requires that the happy person actually construct a suitable life ideal, and that he actually judge, with respect to the whole life that he actually will have lived, that it matches up to some specific degree to that ideal. In addition, WLS1 requires the happy person to have a comprehensive conception of the life about which he is making this judgment, and it requires him to make a favorable judgment with respect to that life. I believe that WLS1 is a fair interpretation of the concept of happiness that Tatarkiewicz had in mind in several passages including one of the passages cited at the outset. ${ }^{23}$ If we were to add a clause requiring some sort of favorable emotional attitude, the resulting definition would be similar to Brandt's.

WLS1 introduces a very strange concept of happiness. An incontrovertible empirical fact entails that no actual human being has ever been happy in the sense defined in WLS1. The relevant fact is that no actual human being has the mental capacity to have a sufficiently comprehensive awareness of his whole life from beginning to end. Even Tatarkiewicz, who endorses something like this concept, is well aware of this problem. He says, 'Happiness is to be satisfied with life as a whole; on the other

\footnotetext{
${ }^{23}$ It seems also to be the central view he defends in Tatarkiewicz (1966).
} 
hand, satisfaction of this kind is impossible. It is so because our minds are incapable of comprehending the whole of our life. ${ }^{24}$ As a result, if we define happiness in this way, and then say that a person's welfare level at a time is determined by his happiness level at that time, then we have to say that no actual human being has ever enjoyed positive welfare.

There are various ways in which the requirement for happiness could be weakened. For example, we might replace the universalism of WLS1 with important aspectivalism; we might replace the epistemic demandingness with laxness. The result is:

WLS2: A person, $\mathrm{S}$, is happy to degree $\mathrm{n}$ at a time, $\mathrm{t},=\mathrm{df}$. there is a certain life that $\mathrm{S}$ actually will end up having lived, and at $\mathrm{S}$ actually has a life ideal, and at t, S knows what his life ideal is and has at least a vague conception of what will transpire in his life as a whole, and at $\mathrm{t}, \mathrm{S}$ actually judges with respect to important aspects of his whole life (from beginning to end) that it matches up to degree $\mathrm{n}$ with the life ideal that $\mathrm{S}$ maintains at $\mathrm{t}$.

WLS2 is clearly different from WLS1 (and it is perhaps an improvement). But so long as the definition requires actual judgments about one's life, the central problem will remain. Things could be going well for a person at a time even though he is not making any

\footnotetext{
${ }^{24}$ Tatarkiewicz (1976: 9). It's interesting to see that Tatarkiewicz himself is aware of the epistemic difficulty that arises if happiness is defined in something like WLS1. That independently confirms my claim that he must have been understanding ideal happiness in something like this form. Otherwise, why would he say that it has the unfortunate implications that he cites?
} 
judgment about his life at that time. Imagine that Timmy is a happy-go-lucky guy who has friends, and a job, and an apartment, and a car that he likes. He always has a smile on his face. Suppose we catch him at a time when he is singing and dancing at a party. $\mathrm{He}$ is apparently enjoying himself immensely. We may assume that appropriate "happy" neurotransmitters flowing in abundance in Timmy's brain. Yet Timmy has not given any thought to the project of constructing a life ideal. He has no views about what is "important". If we were to ask him at this moment to reveal his judgment about the extent to which important aspects of his life measure up to his life ideal, he would say that he needs a few minutes to reflect. He never thought about such matters. He has never formed a judgment concerning the extent to which the most important aspects of his life measure up with his life ideal. So if we accept WLS2 as our account of happiness, we will have to say that Timmy is not happy at this moment. If Timmy is always like this, we will have to say that he is never happy. If we use this concept of happiness in our formulation of eudaimonism, we will have to say that Timmy's life is not going well for him. ${ }^{25}$

It seems to me that those who are attracted by the fundamental eudaimonistic intuition would want to say that Timmy is (in the relevant but obscure sense) a very happy person. Accordingly, they would want to say that his life is going well for him. Thus, the concept of happiness defined in WLS2 generates a form of eudaimonism that does not adequately capture the idea that eudaimonists want to endorse.

\footnotetext{
${ }^{25}$ Haybron discusses this problem in Chapter Four of (Haybron, forthcoming). He refers to it as "the problem of attitude scarcity".
} 
Another example highlights a different problem. Imagine some philosopher deeply engaged in philosophical contemplation. Suppose he is thinking about a problem in metaphysics, trying to untangle some profound conceptual knots. Suppose this philosopher is doing philosophy for its own sake - it's not "just a job" to him. He really likes doing philosophy. Suppose that this philosopher is so engrossed in his metaphysical reflections that he is giving no thought whatever to himself or his own life. He is focused entirely on the puzzle at hand and, let us imagine, he is beginning to think he sees a possible solution to the metaphysical puzzle that intrigues him. He is excited about the prospect of solving this puzzle. ${ }^{26}$

The crucial fact about this philosopher is that at the moment described he is not making any judgment about his life as a whole. He is not thinking about his life as a whole. He is not thinking about himself or his circumstances at all. Rather, he is thinking about the metaphysical puzzle. As a result, he is not happy in the sense defined by WLS2; and as a result of that, he would be given a welfare rating of zero by the form of eudaimonism that employs the WLS2 concept of happiness. But surely the philosopher is in fact quite happy at the moment described - he is wholeheartedly engaged in an activity he loves. Those who think that happiness is the good would want to say that the imaginary philosopher is enjoying very high - perhaps maximally high welfare at this moment.

\footnotetext{
${ }^{26}$ I am thinking here of the philosopher as described by Aristotle in Bk. X, Ch. 7 of the Nicomachean Ethics.
} 
This problem would arise with respect to any definition of happiness that requires actual judgments either about whole lives, important aspects of lives, or even some aspects of lives. It would arise for any definition that required such judgments about life as a whole, the current slice of life, or life up till now. I think it would arise if it required a judgment about life as it actually is, or if it required a judgment about life as the happy person takes it to be.

The main critical point here is simple: a person can be very happy at a time even though she is not making any judgment about her life as a whole at that time; she can have a happy life even though she never makes any judgment about her life as a whole. ${ }^{27}$

Some actualist definitions do not require judgment. Such definitions require something more emotional. Consider a version of the view (similar perhaps to Telfer's) that requires nothing more than that the happy person be pleased with his life as a whole.

WLS3: A person, $\mathrm{S}$, is happy to degree $\mathrm{n}$ at a time, $\mathrm{t},=\mathrm{df}$. there is a certain life that $\mathrm{S}$ has lived up until $t$, and at $t, S$ takes pleasure of degree $n$ in the fact that she has lived that life so far.

The concept of happiness defined in WLS3 is more easily satisfied than the one defined in WLS1. It does not require the happy person to have any life ideal; it does not require

\footnotetext{
${ }^{27}$ The actual moral of this story is a bit more complex: you can be happy at a time even though you are not making any judgments about the extent to which you are satisfied with your life up to that time, or about the extent to which you are satisfied with the current slice of your life, or about the important aspects of your life up to that time, etc.
} 
that she make any judgment about her life as a whole; it does not require that she contemplate the way her life is going to progress in the future, or that she have any attitude toward her future prospects. It demands far less. It demands only that the person take pleasure in the life she has so far lived.

Even this modest requirement is still too stringent. To take pleasure in something at a time, one must at least consider that something. One must at least form some thought about that thing. But surely a person could be happy at a time even though he does not at that moment consider the life he has lived up until then. Suppose the metaphysician described earlier is too engrossed in metaphysical contemplation at a certain moment to give any thought to the life he has lived up until today. He may be taking pleasure in the fact that a solution seems to be at hand, but he is not thinking about his own life and is not taking pleasure in any autobiographical facts. If we employ the WLS3 definition of happiness, we will have to say that the metaphysician is not happy at that moment. But in spite of this even someone who endorses the underlying eudaimonistic intuition would want to say that things are going well for the metaphysician and that he is happy. After all, he is happy about ${ }^{28}$ lots of things - primarily in this example he is happy to be on the verge of solving an interesting puzzle in metaphysics. ${ }^{29}$ The main point here is also simple: a person can be happy at a time even though he is not actually pleased about or feeling good about, or otherwise emotionally focused upon his life as a whole; a person can have a happy life even though he never is actually pleased about, or otherwise

\footnotetext{
${ }^{28}$ I here use 'happy' in some vague, pretheoretical, but familiar sense.

${ }^{29}$ The case of Timmy seems to me to establish the same point. While singing and dancing, Timmy is not thinking about his life up until that point. Yet eudaimonists should want to say that his life is going very well for him. He seems to be precisely the sort of person they would describe as "happy".
} 
actually thinking about his life as a whole. ${ }^{30}$ I conclude, then, that every actualist WLS definition gives us a concept of happiness that does not serve well in a eudaimonistic theory of welfare.

Let us turn to hypotheticalism. Let us consider versions of the view that make use of the concept of a "would-be" judgment and a "would-be" life ideal. We can say that a person's happiness level at a time is determined not by the judgment he actually makes at that time about the life ideal he actually has at that time, but by the judgment he would have made at that time if he had made one. Consider this:

WLS4: A person, $\mathrm{S}$, is happy to degree $\mathrm{n}$ at a time, $\mathrm{t},=\mathrm{df}$. at $\mathrm{t}, \mathrm{S}$ is such that if he were to reflect on his life as a whole at $\mathrm{t}$, and if he were to formulate a life ideal at $\mathrm{t}$, he would judge that his life as a whole measures up to degree $\mathrm{n}$ to that ideal.

WLS4 is intended to define a momentary happiness level for every person, for every moment, whether the person makes a judgment at that moment or not. Information about these momentary happiness levels can then be aggregated so as to yield happiness levels for any interval, including a life as a whole. These happiness levels can then be employed in a eudaimonistic theory of welfare.

The case of the unreflective Timmy may now seem to be resolved. Although he did not think about his life, and did not formulate a life ideal, and did not form any

\footnotetext{
${ }^{30}$ The further options mentioned in fn. 27 apply here as well, suitably revised so as to apply to the more purely emotional versions of WLS.
} 
judgments concerning the extent to which his life as a whole measured up to his ideal, it may appear reasonable to suppose that there is, for each moment in his life, a judgment that he would have made if he had thought about his life as a whole in the appropriate ways. These hypothetical judgments then yield happiness levels for all the moments in Timmy's life. These can then be aggregated so as to yield a lifetime happiness level for Timmy. Presumably, the lifetime happiness level would be positive.

It is not entirely clear that the proposed method does yield the requisite numbers. Perhaps there are several different numbers, each of which is such that Timmy might have judged that he is satisfied to that degree if he had been asked about whole life satisfaction. Perhaps if the question were put to him in one way, he would come up with a certain response; but if the question were put to him in a different way, he would come up with a different response. Let us put this worry aside. Maybe there is an ideal way to frame the question. Let us assume that there are such numbers. Are the numbers of genuine theoretical interest? Is happiness so defined relevant to welfare?

Reflecting upon one's life and ideals and considering the extent to which the life measures up to the ideals very well have some impact on a person's emotional state. ${ }^{31}$ Just raising the question might make a person less glum; it might make him less cheerful. Consider the case of Timmy again. He is a happy-go-lucky person who in fact never reflects on his life as a whole and hasn't formulated a life ideal. It is consistent with this to suppose that if he were to think about these things, he would become depressed. He might judge that his life as a whole has been a pointless waste. In such a case it would be

\footnotetext{
${ }^{31}$ This seems to be one of the guiding intuitions behind Cognitive Behavioral Therapy.
} 
cruel to force him to face reality; it would be better to leave him to his happy and unexamined life.

We can imagine that every waking moment of Timmy's adult life is like this: he is cheerful, active, smiling, and engaged in activities that he enjoys at that moment, but also such that if he were to reflect at that moment on his life as a whole, and if he were to formulate a life ideal, he would promptly become despondent and would judge his life as a whole to have been worthless. In this case, the judgments that Timmy would make would not reflect his actual situation. For every moment in his adult life, Timmy's would-be judgment gives a number that is lower than the number that a sensitive eudaimonist would assign to him for that moment. The eudaimonist would focus on such things as his smile, his cheerful activity, his engagement in activities that he apparently likes. Thus, Timmy seems to be very happy. But his happiness is in part dependent upon the fact that he is doing things that he enjoys, rather than thinking about his life and his ideals. $^{32}$ If he were to turn his attention to questions about these things, he would cease being so happy. Thus, the concept defined by WLS4 is not suitable for use in a eudaimonist criterion of welfare. ${ }^{33}$

\footnotetext{
${ }^{32}$ My remarks are not intended to presuppose an undefended commitment to some specific analysis of the concept of happiness. I mention the smile, the cheerfulness, the enjoyment etc. simply because I think these things would normally be taken to be indicators of happiness - even if we haven't got any precise account of the nature of happines s. Whatever precisely happiness may be, Timmy seems to have it.

${ }^{33}$ The opposite problem is also possible. Consider the case of an unhappy person-Tammy. Tammy in fact never formulates any life ideal and never makes judgments of satisfaction. She's just too glum to think about such things. It might be the case that, at every moment of her adult life, she is such that if she had been asked about her life and her ideals, she would have given these matters some thought; and if she had given them some thought, she would have formulated a life ideal, and she would have realized that her life has not been so bad; and as a result of that, she would have been a lot happier than she in fact was. Tammy is thus an ideal candidate for CBT. The proposed theory yields in Tammy's case a number that is much higher than it should be. She is in fact not a happy person, but the theory says that she is.
} 
The case of the contemplative philosopher highlights a different problem for WLS4. Suppose again that at a certain time he is deeply engrossed in philosophical contemplation. He might be like this: he would not think about his life as a whole unless someone were to interrupt him and ask the question; yet if someone were to ask him how he feels about his life as a whole, the interruption would annoy him. He was working on a problem in metaphysics, and now someone is breaking his train of thought and asking him to think about something else - his own life. Perhaps he finds this question trivial and narcissistic. Right at this moment he prefers to be thinking about metaphysics. The implication seems pretty clear: if at the selected moment he were to think about his life as a whole and his ideals, he would report that his life is not matching up very well to his ideals. He would have to say that the match would have been better if he had been permitted to continue thinking about metaphysics rather than his own personal affairs. ${ }^{34}$

It seems to me that what I have said about WLS4 would hold equally for any hypotheticalist concept of WLS happiness. So long as we define a person's happiness level at a moment by appeal to some counterfactual judgment, there is always the chance that the numbers will be wrong.

\footnotetext{
${ }^{34}$ I here assume that the counterfactual judgment that the philosopher makes is a judgment about the satisfactoriness of his whole life at the world in which he is making that judgment. Since that is a world in which his metaphysical contemplation has been interrupted, he is annoyed and judges that things are not going well for him. On a different view, his actual happiness would be determined by the counterfactual judgment that he makes concerning the satisfactoriness of his life as a whole at the actual world. Thus the philosopher would be making a judgment about a life in which there has been no interruption. This vie w gives the wrong assessment in the case of a happy person (like Timmy) who in fact does not make a judgment about his actual life, but who, if he were to make a judgment about his actual life, would judge it to be unsatisfactory.
} 
Some philosophers have suggested that the best form of WLS would be one that defines happiness as the amount of life satisfaction that a subject would have if he were to contemplate his own life from an epistemically ideal perspective. ${ }^{35}$ In one form, the idea is that a person's level of happiness is to be defined as the amount of whole life satisfaction he would have had if he had been fully informed, logically consistent, and not subject to emotional disturbances. The considerations I have raised here are directly relevant to any such hypothetical form of WLS. Consider a person who for all practical purposes seems to be very happy (again using the word 'happy' in some familiar, vague, ordinary sense) but who is also in an epistemically poor situation for life evaluation. Suppose he is confused about the actual circumstances of his life. We may imagine that if he were in an epistemically ideal situation for evaluating his life, he would know much more about his life and he would judge it to be much less satisfactory. His is a case in which the old adage "ignorance is bliss" is apt. But note that the proposed definition would declare him to be unhappy. Obviously, any such conclusion would have no relevance to the question we mean to ask. He is blissful in fact. But his blissfulness is in part dependent upon the fact that he is misinformed about his own life. Thus the happiness rankings generated by the imagined forms of WLS would be wide of the mark.

The opposite case is perhaps even more striking. Suppose Tammy is glum and miserable. She has a frown on her face all the time. She is contemplating suicide. Her misery, let us suppose, is in part due to some faulty judgments. She thinks she is a worthless sinner; she thinks everyone hates her; she thinks her life has been a waste.

\footnotetext{
35 This seems to be at le ast part of what Valerie Tiberius claims in her "How's It Going?" (Tiberius, unpublished) when she speaks of the "reflective perspective", though it should be noted that she is proposing an account of happiness as an evaluative concept, not as an empiricalconcept.
} 
Anyone with eudaimonistic leanings would want to say that Tammy's life is not going well for her. Yet it is consistent with all this to suppose that if Tammy were to view her life from an epistemically ideal perspective, she would find it far more satisfactory. If she knew that she was in fact not a sinner, and that she was in fact well liked by others, she might sincerely declare that her life had matched up in many important ways to her ideals. So an "ideal information" conc ept of WLS happiness would count Tammy as already happy. Thus the proposed definition does not yield the theory of welfare that the eudaimonist finds attractive. The eudaimonist wants to say that Tammy would have been a lot happier and a lot better off if she had been better informed about her circumstances. If we define happiness by appeal to the level of satisfaction Tammy would have had if she had been well informed, we end up saying that she is already very happy and faring well.

\section{Conclusion}

The most popular concepts of happiness among psychologists and philosophers nowadays are WLS concepts of happiness. I have attempted to show that there are hundreds of logically distinct ways in which a WLS conception of happiness can be developed. However, every precise conception is either a version that requires actual satisfaction with life as a whole or a version that requires hypothetical satisfaction with life as a whole. ${ }^{36}$ I have presented considerations designed to show that a person can be

\footnotetext{
${ }^{36}$ To avoid needless repetition, I have not mentioned all the variants. I could have said, 'Or actual satisfaction with the current slice of life, or actual satisfaction with the important aspects, or actual.... etc.'
} 
happy (in any familiar sense that might be relevant to eudaimonism) at a time even though he is not actually making any judgment about his life as a whole at that time. I have also presented considerations designed to show that a person can be happy (again in any relevant sense of term) even though it is not correct to say that if he were to form a judgment about his life as a whole at that time, it would be a favorable judgment. These considerations strongly suggest that those who are attracted by the eudaimonistic intuition ("happiness is the Good") should avoid defining happiness in terms of whole life satisfaction.

\section{References}

Aristotle. (1962). Nicomachean Ethics. New York: Bobbs-Merrill.

Brandt, R. B. (1967). "Happiness." in The Encyclopedia of Philosophy, ed. P. Edwards. New York: The Macmillan Company \& the Free Press, pp. 413-414.

---(1979). A Theory of the Good and the Right. New York: Oxford University Press.

--- (1989). "Fairness to Happiness." Social Theory \& Practice 15, pp. 33-58.

Davis, W. (1981a). "Pleasure and Happiness." Philosophical Studies 39, pp. 305-318.

--- (1981b). “A Theory of Happiness.” American Philosophical Quarterly 18, pp. 111-20. 
Diener, E., R. A. Emmons, et al. (1985). “The satisfaction with life scale.” Journal of Personality Assessment 49, pp.71-75.

Fordyce, M. W. (1988). “A Review of Research on the Happiness Measures: A Sixty Second Index of Happiness and Mental Health." Social Indicators Research 20, pp. 35582.

Haybron, D. M. (2000). “Two Philosophical Problems in the Study of Happiness.” The Journal of Happiness Studies 1:2, pp. 207-225.

--- (2001). "Happiness and Ethical Inquiry: An Essay in the Psychology of Well-Being." Ph.D. Dissertation, Rutgers University.

--- (2007). "Life Satisfaction, Ethical Reflection and the Science of Happiness." The Journal of Happiness Studies, 8:1, 99-138.

--- (forthcoming) The Pursuit of Unhappiness: The Elusive Psychology of Well-Being, Oxford University Press.

Kahneman, D., E. Diener, N. Schwarz, eds. (1999). Well-Being: The Foundations of Hedonic Psychology. New York: Russell Sage Foundation Press. 
Kekes, J. (1982). “Happiness.” Mind 91, pp. 358-76.

--- (1992). "Happiness." In Encyclopedia of Ethics, eds. L. C. Becker and C. B. Becker. New York: Garland, pp. 430-435.

Layard, R. (2005). Happiness: Lessons from a New Science. New York: The Penguin Press.

Mill, J. S. (1962). Utilitarianism in John Stuart Mill: Utilitarianism, On Liberty, and Essay on Bentham, edited with an introduction by Mary Warnock. Cleveland and New York: Meridian Books.

Nettle, D. (2005). Happiness: The Science Behind Your Smile. Oxford: Oxford University Press.

Nozick, R. (1989). The Examined Life. New York: Simon and Schuster.

Sumner, L. W. (1996). Welfare, Happiness, and Ethics. Oxford: The Clarendon Press.

--- (2000). “Something In Between.” In Well-Being and Morality, eds. R. Crisp and B. Hooker. Oxford: Clarendon Press, pp. 1-19. 
--- (2006). “Happiness.” In Encyclopedia of Philosophy $2^{\text {nd }}$ Edition, ed. D. M. Borchert. Detroit: Macmillan Reference, pp. 221-224.

Tatarkiewicz, W. (1966). "Happiness and Time." Philosophy and Phenomenological Research 27, pp. 1-10.

--- (1976). Analysis of Happiness. The Hague: Martinus Nijhoff.

Telfer, E. (1980). Happiness. New York: St. Martin's Press.

Tiberius, Valerie (unpublished). “'How's It Going?’ Judgments of Overall LifeSatisfaction and Philosophical Theories of Well-Being”. Available at http://www.tc.umn.edu/ tiberius/workshop_papers/Tiberius.pdf 